\title{
Association of Marital Status and Marital Transition With Metabolic Syndrome: Tehran Lipid and Glucose Study
}

\author{
Somayeh Hosseinpour-Niazi ${ }^{1,2}$; Parvin Mirmiran ${ }^{3}$; Farhad Hosseinpanah ${ }^{1}$; Arefeh Fallah- \\ ghohroudy ${ }^{1,2}$; Fereidoun Azizi ${ }^{4, *}$ \\ ${ }^{1}$ Nutrition and Endocrine Research Center, Research Institute for Endocrine Sciences, Shahid Beheshti University of Medical Sciences, Tehran, IR Iran \\ 2 Obesity Research Center, Research Institute for Endocrine Sciences, Shahid Beheshti University of Medical Sciences, Tehran, IR Iran \\ ${ }^{3}$ Department of Clinical Nutrition and Dietetics, Faculty of Nutrition Sciences and Food Technology, National Nutrition and Food Technology Research Institute, Shahid Beheshti \\ University of Medical Sciences, Tehran, IR Iran \\ ${ }^{4}$ Endocrine Research Center, Research Institute for Endocrine Sciences, Shahid Beheshti University of Medical Sciences, Tehran, IR Iran \\ ${ }^{*}$ Corresponding author: Fereidoun Azizi, Endocrine Research Center, Research Institute for Endocrine Sciences, Shahid Beheshti University of Medical Sciences, P. O. Box: 193954763, \\ Tehran, IR Iran. Tel: +98-2122357484, Fax:+98-2122416264;+98-2122402463, E-mail: azizi@endocrine.ac.ir
}

Received: March 16, 2014; Revised: June 23, 2014; Accepted: August 04, 2014

\begin{abstract}
Background: Most existing reports indicate that body weight gradually increases following marital status and thereby enhances health status and decreases mortality; however, the association between marital status and the metabolic syndrome (MetS) has not been thoroughly investigated in a longitudinal study.

Objectives: The aim of this study was to investigate the potential effects of marital status and marital transition on MetS during a 9.6-year follow-up in Tehran Lipid and Glucose Study.

Patients and Methods: For this study, 5221 participants (2060 males and 3161 females), aged 15 to 90 years at baseline, were followed for a median of 9.6 years. Marital status was categorized as consistent marital status and marital transition. We measured MetS risk z score and its components and calculated their changes. Then the effects of marital status and marital transition on MetS risk $z$ score and its components were assessed using multivariable linear regression.

Results: In comparison to participants who were married, no significant changes in MetS risk $z$ score was found in single participants. Employed females in the transition to married group had significant increase in MetS risk $z$ score than single employed females. No significant changes in MetS risk zscore were observed between widowed/divorced subjects and compared to consistently married subjects. Conclusions: Marital status may affect MetS riskz score differently in both genders.
\end{abstract}

Keywords:Marital Status; Metabolic Syndrome X; Marital Transition

\section{Background}

Metabolic syndrome (MetS) refers to the constellation of metabolic abnormalities including glucose intolerance, abdominal obesity, dyslipidemia, and hypertension (1). The prevalence of MetS in Iran is high; with a prevalence rate of over $30 \%$ in the adult population, this epidemic would escalate over the next decade $(2,3)$. In a previous study among adults of Tehran with 9.6-year follow-up, the incidence of MetS by adult treatment panel III and international diabetes federation criteria was 31 and 39 per 1000 population per years, respectively (4). This syndrome was associated with an increased risk of chronic diseases, including diabetes, cardiovascular disease (CVD), and chronic kidney disease (5, 6). Genetic, metabolic, environmental, and social factors have all been reported as the risk factors for MetS $(7,8)$. Social factors, which are determined by the education level, occupation, income, and marital status, may influence MetS and its components by affecting environmental factors such as dietary behavior, food intake, and physical activ- ity as important contributing factor to MetS $(9,10)$. Although social factors such as education level, occupation, and income have been well studied for their association with MetS (11-13), marital status, as an important feature of social factors, has not been evaluated in that regard $(14,15)$. Few studies have investigated the associations between marital status and MetS, most of them have crosssectional design that investigated current marital status (16-18), and few studies investigated the effect of change in marital status on MetS and its components (19).

\section{Objectives}

Hence, the aim of this study was to investigate the association of marital status andmarital transition with Mets and its components in a sample population in Tehran, who were selected from participants of the Tehran Lipid and Glucose Study (TLGS).

\section{Patients and Methods}

The TLGS is a community-based prospective study,

Copyright (C) 2014, Research Institute For Endocrine Sciences and Iran Endocrine Society; Published by Kowsar. This is an open-access article distributed under the terms of the Creative Commons Attribution-NonCommercial 4.0 International License (http://creativecommons.org/licenses/by-nc/4.0/) which permits copy and redistribute the material just in noncommercial usages, provided the original work is properly cited. 
aimed at preventing noncommunicable disease by development of a program to promote healthy lifestyles and reduce noncommunicable disease risk factors. This study is being conducted on a sample of residents under the coverage of three medical health centers in District 13 of Tehran, the capital of Iran. Details of the survey have been reported elsewhere (20). In the TLGS, 15005 individuals, aged $\geq 3$ years, living in district 13 of Tehran, were selected by multistage cluster random sampling methods and were tracked (21); participants underwent physical examination and completed follow-up questionnaires to update information on marital status and medical histories (21). The baseline survey was performed in 1999 and follow-up surveys took place every three years. For the present study, of 15005 individuals, 12030 subjects, aged $\geq 15$ years, were evaluated in the cross-sectional phase 1 of TLGS from 1999 to 2001; at baseline 694 participants were excluded because they did not have complete baseline data. In addition, 6115 participants were excluded, because they did not have all the relevant information for the covariate adjustment and complete data on components of MetS at three follow-ups or they experienced inconsistent transitions between consecutive time points. The final sample included 5221 participants (2060 males and 3161 females), aged 15 to 90 years, who were followed for a median period of 9.6 years. Compared with nonresponders $(n=6115)$, respondents $(n=5221)$ had no difference regarding the mean of their age (40.1 $\pm 19.2 \mathrm{vs}$. $42.2 \pm 19.8$ year) and body mass index (BMI) (26.1 \pm 4.4 vs. $25.9 \pm 4.1 \mathrm{~kg} / \mathrm{m}^{2}$ ), but were more likely to be single in 1999 (30.4\% vs.19.4\%; $\mathrm{P}<0.001$ ). In addition, there was no significant different between physical activity level, smoking status, and occupational status among responders and nonresponders.

\subsection{Assessment of Variables}

Weight was measured while the participants were minimally clothed and not wearing shoes, using digital scales (Seca, Hamburg, Germany) and measures were rounded to the nearest $100 \mathrm{~g}$. Height was measured while participants were standing without shoes, with their shoulders in a normal position, using a tape fixed to the wall, and measures were rounded to the nearest $0.5 \mathrm{~cm}$. BMI was calculated as weight $(\mathrm{kg})$ divided by square of height $\left(\mathrm{m}^{2}\right)$. Waist circumference (WC) was measured at the level of the umbilicus, using an outstretched tape meter, without pressure to body surfaces and was rounded to the nearest $0.5 \mathrm{~cm}$. Systolic and diastolic blood pressure (SBP and DBP, respectively) were measured twice in a sitting position on the right arm, after 15 minutes rest and the mean of the two measurements was considered as the subject's blood pressure.

Physical activity level was assessed in the first phase of the TLGS using Lipid Research Clinic questionnaire (22). Cigarette smoking status was categorized as current smoker, nonsmoker, or ex-smoker. Additional covariate information including age, educational levels, occupational status, medical history, and current use of medications was obtained using an oral questionnaire.

\subsection{Laboratory Measurements}

After 12 to 14 hours of overnight fasting, blood samples were drawn from all study participants into vacutainer tubes in a sitting position. All blood analyses were done at the TLGS research laboratory on the day of blood collection, and analyses were conducted using a Selectra 2 autoanalyzer (Vita Scientific, Spankeren, the Netherlands). Serum triglyceride (TG) concentrations were measured using TG kits (Pars Azmoon Inc., Tehran, Iran) by the enzymatic colorimetric test with glycerol phosphate oxidase. HDL cholesterol was measured after precipitation of the apolipoprotein B-containing lipoproteins with phosphotungstic acid. Fasting blood sugar (FBS) was assayed using an enzymatic colorimetric method with glucose oxidase technique. Inter-assay and intra-assay coefficients of variations were both $2.2 \%$ for FBS, $2 \%, 0.5 \%$ for HDL and total cholesterol, $1.6 \%$ and $0.6 \%$ for TG, respectively.

\subsection{Definitions of Marital Situations}

Marital status was categorized into marital transition and consistent marital status. Marital transition was categorized as transition "to" and "out" of marriage; "transition to marriage status" included change in marital status from divorced, widowed, or single to married whereas "transition out of marriage" included change in marital status from married to divorced or widowed during the follow-up. Subjects who did not experience marital transitions during follow-up were categorized as having "consistent marital status" including consistent single, married, and divorced/widowed. The category of marital transition and marital status resulted in ten possible categories (Table 1). Because of the limited numbers of participants in the widowed and divorced, these subjects were considered as a single category. Therefore, the main analyses were performed for five categories including consistent single, consistent married, consistent divorced/widowed, transition to married, and transition out of marriage.

\subsection{Definition of Metabolic Syndrome Risk z Score}

A z score was computed as the number of SD units from the sample mean, i.e. $z=[($ value-mean $) / S D]$, for each of the component of MetS. A continuous MetS risk $z$ score was derived by summing the $z$ score of WC, SBP,DBP, FBS, HDL cholesterol, and TG concentrations; this $z$ score was then divided by six to product the MetS risk score with units of SD (23).

\subsection{Statistical Analysis}

The SPSS (version 15.0; SPSS Inc, Chicago, IL) was used for all statistical analyses. One-way ANOVA and Chi square 
Hosseinpour-Niazi S et al.

Table 1. Marital Status Changes Between Baseline and Follow-up in Study Participants: Tehran Lipid and Glucose Study, 1999-2011 a

\begin{tabular}{lccc}
\hline & Males & Unemployed Females & Employed Females \\
\hline Single-Single & $191(9.8)$ & $43(1.9)$ & $171(23.3)$ \\
Married-Married & $1464(74.9)$ & $1775(79.3)$ & $215(29.3)$ \\
Divorced-Divorced & $3(0.2)$ & $11(0.5)$ & $12(1.6)$ \\
Widowed-Widowed & $3(0.2)$ & $111(5.0)$ & $69(9.5)$ \\
Single-Married & $245(12.3)$ & $57(2.5)$ & $218(29.7)$ \\
Single-Divorced/Widowed & $1(0.1)$ & $2(0.1)$ & $6(0.8)$ \\
Married-Divorced & $19(1.0)$ & $15(0.7)$ & $12(1.6)$ \\
Married-Widowed & $23(1.2)$ & $214(9.5)$ & $17(2.3)$ \\
Divorced-Remarried & $3(0.2)$ & $3(0.1)$ & $8(1.2)$ \\
Widowed-Remarried & $2(0.1)$ & $8(0.4)$ & $5(0.7)$ \\
\hline a Data & & &
\end{tabular}

a Data are presented as No. (\%).

were used respectively for quantitative and qualitative variablesto detect differences in general characteristics. Changes in components of MetS and MetS risk $z$ score were calculated as follows:

(component of MetS and MetS risk $z$ score at follow-up -the component of MetS and MetS risk $z$ score at baseline)/components of MetS and MetS risk $z$ score at baseline

Multivariable adjusted linear regression model was used to estimate the association of consistent marital status and marital transition with changes in component of MetS and MetS risk $z$ score. In consistent marital status, components of MetS and the MetS risk $z$ score of single or widowed/divorced participants were compared to those of married ones. For transition to married, the reference group consisted of participants who were consistently single during follow-up. For transition out of marriage, the reference group consisted of subjects who were consistently married during followup. In multivariable models, we controlled for age (continuous), smoking status (smoker, nonsmoker, and ex-smoker), and physical activity (light, moderate, and heavy), and education levels (primary and secondary, high school, and university), and duration of change in marital status.

There was a significant effect of interactions by sex on the association of marital status and MetS $z$ score. In addition, among females, there was a significant effect of interactions by occupational status on the association of marital status and marital transition with MetS $z$ score. Therefore, the analysis was done separately according to sex and among females by occupations.

\section{Results}

The mean age of participants at baseline was $40.5 \pm$ 15.2 years. Baseline characteristics of the participants according to marital status are shown in Tables 2 and 3. In both sexes, widowed/divorced subjects were older and less educated in comparison with married and single subjects. Except for age, there was no significant difference in characteristics between subjects in transition to and out of marriage.

Table 4 shows multivariable mean changes of the components of MetS and MetS risk $z$ score among consistent marital status. In comparison to changes in participants who remained consistently married, DBP of single males and females (both employed and unemployed) was decreases by -5.4 (95\% CI,-8.1 to -2.7), -4.3 (95\% CI,-8.6 to -0.1), and $-4.3 \mathrm{~mm} \mathrm{Hg}$ (95\% CI,-8.1 to -0.6), respectively. Moreover, in comparison with married males, single males had a significant decrease in FBS and a significant increase in BMI, WC, and TG concentrations after controlling for confounding factors. In comparison to married participants, no significant changes in MetS risk $z$ score were found in consistently single participants. Among widowed/divorced subjects, no significant changes were observed in components of MetS and MetS risk $z$ score in comparison with married subjects.

Table 5 shows multivariable mean changes in components of MetS and the MetS risk $z$ score among participants with marital transition. In comparison to those who remained consistently married and in the transition to married status, males and females (both employed and unemployed) had BMI increases by 2.9 (95\% CI,0.45-5.3), 10.3 (95\% CI,5.6-14.9), and $7.6 \mathrm{~kg} / \mathrm{m}^{2}$ (95\% CI,4.9-10.4), respectively. In comparison to single employed females, employed females with transition to married status had significant decreases in HDL cholesterol concentrations and a significant increase in WC, TG concentrations, and MetS risk $z$ score after controlling for confounding factors. In comparison to married subjects and after controlling for confounding factors, no significant changes were found in MetS risk $z$ score and its components among all participants in the transition out of married status, except for employed females who had a significant decrease in SBP. 
Hosseinpour-Niazi S et al.

Table 2. Baseline Characteristics of Participants According to Marital Status and Marital Transition Among Males; Tehran Lipid and Glucose Study, 1999-2011 a,b,c

\begin{tabular}{|c|c|c|c|c|c|}
\hline & \multicolumn{3}{|c|}{ Consistent Marital Status } & \multicolumn{2}{|c|}{ Marital Transition } \\
\hline & Single & Married & Widowed/Divorced & Transition to Marriage & Transition Out of Marriage \\
\hline Male, No. & 191 & 1463 & 5 & 250 & 43 \\
\hline Age, y & $20.5 \pm 6.0$ & $47.4 \pm 12.7$ & $63.0 \pm 12.6$ & $23.2 \pm 7.0$ & $53.95 \pm 18.8$ \\
\hline \multicolumn{6}{|l|}{ Physical Activity, \% } \\
\hline Light & 28.1 & 19.2 & 42.9 & 30.8 & 20.9 \\
\hline Moderate & 26.1 & 14.9 & 14.3 & 24.3 & 23.3 \\
\hline Heavy & 43.3 & 63.9 & 42.9 & 44.9 & 55.8 \\
\hline \multicolumn{6}{|l|}{ Level of Education, \% } \\
\hline Primary and Secondary & 54.0 & 53.0 & 86.1 & 51.3 & 76.1 \\
\hline High School & 35.7 & 41.8 & 11.7 & 40.4 & 20.6 \\
\hline University & 10.3 & 5.1 & 2.2 & 8.3 & 3.3 \\
\hline \multicolumn{6}{|l|}{ Occupational status, $\%$} \\
\hline Employed & 10.9 & 20.1 & 40.2 & 77.3 & 13.2 \\
\hline Unemployed & 89.1 & 79.9 & 59.8 & 22.7 & 86.8 \\
\hline Current Smoker, \% & 12.7 & 22.8 & 0.0 & 14.3 & 18.6 \\
\hline BMI at Baseline, $\mathrm{kg} / \mathrm{m}^{2}$ & $22.4 \pm 4.8$ & $26.4 \pm 3.7$ & $25.1 \pm 3.5$ & $23.5 \pm 4.4$ & $24.6 \pm 3.8$ \\
\hline $\mathrm{WC}, \mathrm{cm}$ & $76.6 \pm 12.4$ & $90.7 \pm 10.4$ & $87.2 \pm 13.6$ & $79.6 \pm 11.9$ & $87.0 \pm 10.7$ \\
\hline SBP, mm Hg & $112.9 \pm 12.8$ & $121.7 \pm 17.9$ & $119 \pm 18.9$ & $115.3 \pm 12.3$ & $123 \pm 19.2$ \\
\hline DBP, mm Hg & $74.8 \pm 9.7$ & $78.7 \pm 10.5$ & $76.4 \pm 10.4$ & $74.3 \pm 10.0$ & $77.2 \pm 10.9$ \\
\hline FBS, $\mathrm{mg} / \mathrm{dL}$ & $88.2 \pm 8.3$ & $99.1 \pm 29.5$ & $105.0 \pm 31.7$ & $87.3 \pm 11.3$ & $97.3 \pm 19.4$ \\
\hline TG, mg/dL & $130 \pm 81.3$ & $193 \pm 121$ & $174 \pm 86.2$ & $138 \pm 82.1$ & $185 \pm 116$ \\
\hline HDL cholesterol, mg/dL & $40.4 \pm 9.3$ & $38.0 \pm 8.8$ & $33.8 \pm 4.0$ & $39.2 \pm 8.7$ & $41.3 \pm 10.8$ \\
\hline MetS risk $z$ score & $0.03 \pm 0.5$ & $0.024 \pm 0.52$ & $-0.14 \pm 0.5$ & $0.04 \pm 0.5$ & $0.03 \pm 0.5$ \\
\hline
\end{tabular}

Table 3. Baseline Characteristics of Participants According to Marital Status and Marital Transition Among Females; Tehran Lipid and Glucose Study, 1999-2011 a,b,c

\begin{tabular}{|c|c|c|c|c|c|}
\hline & \multicolumn{3}{|c|}{ Consistent Marital Status } & \multicolumn{2}{|c|}{ Marital Transition } \\
\hline & Single & Married & Widowed/Divorced & Transition to Marriage & Transition Out of Marriage \\
\hline Female, No. & 214 & 1991 & 204 & 299 & 266 \\
\hline Age, y & $23.5 \pm 9.6$ & $40.5 \pm 11.5$ & $57.4 \pm 10.8$ & $21.4 \pm 9.5$ & $51.8 \pm 12.8$ \\
\hline \multicolumn{6}{|l|}{ Physical Activity, \% } \\
\hline Light & 25.6 & 25.8 & 28.4 & 30.4 & 26.7 \\
\hline Moderate & 22.0 & 11.5 & 16.3 & 22.2 & 16.6 \\
\hline Heavy & 50.7 & 61.4 & 54.3 & 47.4 & 56.8 \\
\hline \multicolumn{6}{|l|}{ Level of Education, \% } \\
\hline Primary and Secondary & 10.9 & 20.1 & 40.2 & 77.3 & 13.2 \\
\hline High School & 89.1 & 79.9 & 59.8 & 22.7 & 86.8 \\
\hline \multicolumn{6}{|l|}{ University } \\
\hline Occupational status, $\%$ & 54.0 & 53.0 & 86.1 & 51.3 & 76.1 \\
\hline Employed & 35.7 & 41.8 & 11.7 & 40.4 & 20.6 \\
\hline Unemployed & 10.3 & 5.1 & 2.2 & 8.3 & 3.3 \\
\hline Current Smoker, \% & 2.9 & 2.6 & 0.9 & 0.4 & 1.5 \\
\hline BMIat Baseline, $\mathrm{kg} / \mathrm{m}^{2}$ & $22.7 \pm 3.9$ & $27.2 \pm 4.4$ & $28.6 \pm 4.1$ & $22.5 \pm 4.3$ & $28.4 \pm 4.7$ \\
\hline $\mathrm{WC}, \mathrm{cm}$ & $74.0 \pm 8.8$ & $88.3 \pm 11.7$ & $92.9 \pm 10.7$ & $73.6 \pm 10.1$ & $91.9 \pm 12.1$ \\
\hline SBP, mm Hg & $108.5 \pm 11.8$ & 117. \pm 18.0 & $129 \pm 20.4$ & $107 \pm 11.3$ & $127 \pm 22.8$ \\
\hline DBP, mm Hg & $74.1 \pm 8.6$ & $77.7 \pm 10.2$ & $80.4 \pm 9.5$ & $72.6 \pm 8.8$ & $80.8 \pm 11.1$ \\
\hline FBS, mg/dL & $86.6 \pm 8.4$ & $95.5 \pm 28.4$ & $115.4 \pm 52.2$ & $86.4 \pm 9.2$ & $102 \pm 38.2$ \\
\hline $\mathrm{TG}, \mathrm{mg} / \mathrm{dL}$ & $112.7 \pm 60.4$ & $162 \pm 99.2$ & $209 \pm 123.7$ & $105 \pm 66.8$ & $185 \pm 129$ \\
\hline HDL Cholesterol, mg/dL & $45.7 \pm 11.3$ & $44.5 \pm 11.0$ & $44.9 \pm 10.5$ & $45.3 \pm 11.2$ & $45.3 \pm 10.9$ \\
\hline MetS Risk $z$ Score & $0.037 \pm 0.4$ & $0.038 \pm 0.5$ & $0.03 \pm 0.5$ & $0.05 \pm 0.5$ & $0.04 \pm 0.5$ \\
\hline
\end{tabular}


Table 4. Multivariate Mean Percent Changes in Metabolic Syndrome Risk $z$ Score and its Components During Follow-up Among Single and Widowed/Divorced Subjects in Comparison With Consistently Married Subjects; Tehran Lipid and Glucose Study, 1999-2011 a,b

\begin{tabular}{|c|c|c|c|c|c|c|c|c|c|c|c|c|}
\hline \multirow[b]{3}{*}{ BMI, $\mathrm{kg} / \mathrm{m}^{2}$} & \multicolumn{6}{|c|}{ Single } & \multicolumn{6}{|c|}{ Widow/Divorce } \\
\hline & \multicolumn{2}{|c|}{$\begin{array}{l}\text { Males (Rf. Mar- } \\
\text { ried Males) }\end{array}$} & \multicolumn{2}{|c|}{$\begin{array}{c}\text { Unemployed } \\
\text { Females (Rf. Mar- } \\
\text { ried Unemployed } \\
\text { Females) }\end{array}$} & \multicolumn{2}{|c|}{$\begin{array}{c}\text { Employed } \\
\text { Females(Rf. Married } \\
\text { Employed Females) }\end{array}$} & \multicolumn{2}{|c|}{$\begin{array}{l}\text { Males (Rf. } \\
\text { Married } \\
\text { Males) }\end{array}$} & \multicolumn{2}{|c|}{$\begin{array}{l}\text { Unemployed } \\
\text { Females (Rf. } \\
\text { Married Unem- } \\
\text { ployed Females) }\end{array}$} & \multicolumn{2}{|c|}{$\begin{array}{l}\text { Employed Fe- } \\
\text { males (Rf. Mar- } \\
\text { ried Employed } \\
\text { Females) }\end{array}$} \\
\hline & MP & $\mathrm{CI}$ & MP & $\mathrm{CI}$ & MP & $\mathrm{CI}$ & MP & $\mathrm{CI}$ & MP & $\mathrm{CI}$ & MP & $\mathrm{CI}$ \\
\hline Model 1 & $13.6^{\mathrm{C}}$ & 12.1 to 15.0 & -3.9 & $\begin{array}{c}-22.5 \text { to } \\
14.6\end{array}$ & $2.8^{\mathrm{C}}$ & 0.4 to 5.3 & NA & NA & -4.2 & -15.3 to 6.7 & $-3.1^{\mathrm{c}}$ & -5.8 to -0.4 \\
\hline Model 2 & $6.7^{c}$ & 5.0 to 8.4 & -4.1 & $\begin{array}{c}-22.8 \text { to } \\
14.6\end{array}$ & 0.5 & -2.6 to 3.7 & NA & NA & -3.9 & -15.6 to 7.7 & 0.6 & -2.7 to 4.0 \\
\hline
\end{tabular}

\section{WC, $\mathbf{c m}$}

\begin{tabular}{|c|c|c|c|c|c|c|c|c|c|c|c|c|}
\hline Model 1 & $13.6^{\mathrm{C}}$ & 12.3 to 14.9 & -2.7 & -6.0 to 0.6 & 2.0 & -0.4 to 4.5 & NA & NA & -1.2 & -3.2 to 0.7 & $-3.3^{c}$ & -6.2 to -0.4 \\
\hline Model 2 & $7.1^{c}$ & 5.6 to 8.6 & $-4.0^{\mathrm{C}}$ & -7.5 to -0.5 & 2.1 & -1.1 to 5.4 & NA & NA & 1.5 & -1.0 to 4.1 & -0.3 & -4.6 to 3.0 \\
\hline \multicolumn{13}{|c|}{ SBP, mm Hg } \\
\hline Model 1 & -1.9 & $\begin{array}{c}-3.8 \text { to } \\
0.02\end{array}$ & -3.4 & -7.3 to 0.4 & $-4.6^{\mathrm{c}}$ & -7.2 to -1.9 & NA & NA & 0.3 & -2.0 to 2.7 & -0.2 & -3.6 to 3.2 \\
\hline Model 2 & -2.1 & -4.5 to 0.3 & -3.4 & -7.5 to 0.7 & -1.7 & -5.3 to 1.8 & NA & NA & 0.4 & -2.6 to 3.4 & 2.3 & -2.6 to 7.2 \\
\hline
\end{tabular}

DBP, $\mathrm{mm} \mathrm{Hg}$

\begin{tabular}{|c|c|c|c|c|c|c|c|c|c|c|c|c|}
\hline Model 1 & 1.4 & -0.7 to 3.6 & -2.1 & -6.2 to 2.0 & $-4.4^{\mathrm{C}}$ & -7.2 to -1.6 & NA & NA & $-2.8^{\mathrm{C}}$ & -5.3 to -0.4 & $-5.5^{c}$ & -8.8 to -2.1 \\
\hline Model 2 & $-5.4^{\mathrm{C}}$ & -8.1 to -2.7 & $-4.3^{c}$ & -8.6 to -0.1 & $-4.3^{C}$ & -8.1 to -0.6 & NA & NA & 0.2 & -2.9 to 3.3 & 2.8 & -1.8 to 7.4 \\
\hline \multicolumn{13}{|c|}{ FBS, mg/dL } \\
\hline Model 1 & $-6.1^{c}$ & -9.5 to- 2.7 & -6.5 & -14.4 to 1.4 & $-3.0^{C}$ & -5.9 to -0.3 & NA & NA & -2.4 & -7.4 to 2.4 & 0.6 & -3.8 to 5.1 \\
\hline Model 2 & $-8.3^{c}$ & -12.4 to -4.1 & -5.0 & -13.1 to 3.1 & 0.8 & -2.9 to 4.6 & NA & NA & -3.6 & -9.8 to 2.6 & -0.1 & -6.1 to 6.0 \\
\hline
\end{tabular}

TG, mg/dL

\begin{tabular}{|l|lllllllllllll}
\hline Model 1 & 4.8 & -4.6 to 14.3 & -8.5 & -23.6 to 6.5 & $-16.4^{\mathrm{C}}$ & -27.1 to -5.7 & NA & NA & -9.1 & -18.1 to 0.1 & $-23.6^{\mathrm{C}}$ & -36.8 to \\
-10.5
\end{tabular}

\begin{tabular}{|c|c|c|c|c|c|c|c|c|c|c|c|c|}
\hline Model 1 & -2.8 & -6.3 to 0.7 & -0.4 & -7.7 to 7.0 & 6.7 & 1.7 to 11.8 & NA & NA & -3.4 & -7.9 to 0.9 & 1.9 & -4.3 to 8.3 \\
\hline Model 2 & -2.1 & -6.4 to 2.2 & -1.3 & -9.1 to 6.3 & 2.4 & -4.3 to 9.2 & NA & NA & -2.5 & -8.2 to 3.2 & 1.3 & -8.1 to 10.8 \\
\hline
\end{tabular}

MetS Risk $z$ Score

\begin{tabular}{|c|c|c|c|c|c|c|c|c|c|c|c|c|}
\hline Model 1 & 0.16 & -6.7 to 19.7 & -16.0 & -12.6 to 9.4 & -29.8 & $\begin{array}{c}-40.8 \text { to } \\
17.8\end{array}$ & NA & NA & 6.2 & $\begin{array}{c}-10.6 \text { to } \\
13.5\end{array}$ & 16.6 & -7.7 to 21.0 \\
\hline Model 2 & 0.14 & -7.4 to 17.2 & -17.8 & $\begin{array}{c}-11.6 \text { to } \\
10.8\end{array}$ & -23.9 & $\begin{array}{c}-42.8 \text { to } \\
19.5\end{array}$ & NA & NA & 9.4 & $\begin{array}{c}-10.0 \text { to } \\
17.8\end{array}$ & 17.1 & $\begin{array}{c}-10.0 \text { to } \\
22.4\end{array}$ \\
\hline
\end{tabular}

a Abbreviations: Rf, reference group for comparison; NA, non-applicable; MP, mean percent; CI, confidence interval; BMI, body mass index; WC, waist circumference; SBP, systolic blood pressure; DBP, diastolic blood pressure; FBS, fasting blood glucose; TG, triglyceride; and MetS, metabolic syndrome. b Model 1 was adjusted for age (continuous), smoking status (smoker, nonsmoker, and ex-smoker), physical activity (light, moderate, and heavy), education levels (primary and secondary, high school, and university), duration of change in marital status, and baseline variables. Model 2 was further adjusted for BMI.

c $\mathrm{P}<0.05$. 
Table 5. Multivariate Mean Percent Change in Metabolic Syndrome Risk $z$ Score and its Components During Follow-up; Tehran Lipid and Glucose Study, 1999-2011 a,b

\begin{tabular}{|c|c|c|c|c|c|c|c|c|c|c|c|c|}
\hline \multirow[b]{3}{*}{ BMI, $\mathrm{kg} / \mathrm{m}^{2}$} & \multicolumn{6}{|c|}{ Transition to Married Status } & \multicolumn{6}{|c|}{ Transition Out of Married Status } \\
\hline & \multicolumn{2}{|c|}{$\begin{array}{l}\text { Males(Rf. Con- } \\
\text { sistently Single } \\
\text { Males) }\end{array}$} & \multicolumn{2}{|c|}{$\begin{array}{c}\text { Unemployed } \\
\text { Females (Rf. } \\
\text { Consistently } \\
\text { Single Un- } \\
\text { employed } \\
\text { Females) }\end{array}$} & \multicolumn{2}{|c|}{$\begin{array}{l}\text { Employed } \\
\text { Females } \\
\text { (Rf. Consis- } \\
\text { tently Single } \\
\text { Employed } \\
\text { Females) }\end{array}$} & \multicolumn{2}{|c|}{$\begin{array}{c}\text { Males (Rf. } \\
\text { Consistently } \\
\text { Married Males) }\end{array}$} & \multicolumn{2}{|c|}{$\begin{array}{l}\text { Unemployed } \\
\text { females (Rf. } \\
\text { Consistently } \\
\text { Married } \\
\text { Unemployed } \\
\text { Females) }\end{array}$} & \multicolumn{2}{|c|}{$\begin{array}{l}\text { Employed Fe- } \\
\text { males (Rf. Con- } \\
\text { sistently Mar- } \\
\text { ried Employed } \\
\text { Females) }\end{array}$} \\
\hline & MP & $\mathrm{CI}$ & MP & $\mathrm{CI}$ & MP & $\mathrm{CI}$ & MP & CI & MP & $\mathrm{CI}$ & MP & $\mathrm{CI}$ \\
\hline Model1 & -0.01 & -2.5 to 2.5 & $11.4^{\mathrm{C}}$ & 6.6 to 16.3 & $7.8^{c}$ & 5.1 to 10.5 & 1.32 & -1.3 to 4.0 & -3.2 & -11.3 to 4.7 & 0.3 & -3.8 to 4.4 \\
\hline Model 2 & $2.9^{c}$ & 0.45 to 5.3 & $10.3^{c}$ & 5.6 to 14.9 & $7.6^{c}$ & 4.9 to 10.4 & $2.8^{c}$ & 0.3 to 5.3 & -2.9 & -11.4 to 5.6 & 0.6 & -3.3 to- 0.12 \\
\hline \multicolumn{13}{|l|}{ WC, $\mathbf{c m}$} \\
\hline Model 1 & -0.7 & -3.2 to 1.7 & $8.4^{\mathrm{c}}$ & 3.2 to 13.6 & $5.5^{\mathrm{c}}$ & 3.0 to 8.2 & 1.5 & -0.9 to 4.0 & -1.2 & -2.7 to 0.3 & 2.7 & -1.5 to 7.0 \\
\hline Model 2 & 2.1 & -4.0 to 4.5 & $8.2^{\mathrm{c}}$ & 2.6 to 13.8 & $5.4^{\mathrm{c}}$ & 2.8 to 8.1 & $2.7^{c}$ & 0.2 to 5.3 & 1.4 & -0.4 to 3.2 & 3.1 & -1.4 to 7.7 \\
\hline \multicolumn{13}{|l|}{ SBP, mm Hg } \\
\hline Model 1 & -0.8 & -2.7 to 1.2 & 0.9 & -3.3 to 5.2 & 2.0 & -0.4 to 4.4 & 1.2 & -2.7 to 5.2 & -0.1 & -1.9 to 1.7 & $-6.3^{c}$ & -11.1 to -1.4 \\
\hline Model 2 & -0.2 & -2.3 to 1.8 & 0.5 & -3.6 to 4.6 & 1.8 & -0.6 to 4.3 & 1.1 & -3.1 to 5.4 & -0.6 & -2.7 to 1.5 & $-5.6^{\mathrm{c}}$ & -10.7 to -0.5 \\
\hline \multicolumn{13}{|l|}{ DBP, mm Hg } \\
\hline Model1 & 2.7 & -0.3 to 5.7 & 2.8 & -2.1 to 7.9 & 1.3 & -1.5 to 4.3 & 3.6 & -0.6 to 8.0 & $-2.7^{C}$ & -4.6 to- 0.8 & $-5.5^{c}$ & -10.2 to -0.8 \\
\hline Model 2 & 2.4 & -0.7 to 5.6 & 2.2 & -3.0 to 7.5 & 1.5 & -1.4 to 4.4 & 3.5 & -0.9 to 8.1 & -1.3 & -3.5 to 0.9 & -4.7 & -9.6 to 0.1 \\
\hline \multicolumn{13}{|l|}{ FBS, mg/dL } \\
\hline Model1 & $6.0^{c}$ & 2.8 to 9.2 & 1.8 & -2.9 to 6.7 & -0.7 & -3.2 to 1.7 & -0.4 & -7.5 to 6.6 & 1.1 & -2.4 to 4.7 & -1.8 & -6.5 to 2.9 \\
\hline Model 2 & $3.8^{c}$ & 0.5 to 7.4 & 2.5 & -2.1 to 7.3 & -0.3 & -2.7 to 2.2 & -0.3 & -8.0 to 7.4 & -1.7 & -5.9 to 2.4 & -2.0 & -7.1 to 3.1 \\
\hline
\end{tabular}

TG Concentrations, mg/

dL

\begin{tabular}{|c|c|c|c|c|c|c|c|c|c|c|c|c|}
\hline Model 1 & 11.1 & -1.8 to 23.9 & 7.2 & -8.8 to 23.4 & $17.2^{\mathrm{C}}$ & 7.2 to 27.3 & -1.5 & -16.7 to 13.7 & $-11.9^{\mathrm{C}}$ & -18.6 to -5.2 & -18.4 & -38.1 to 1.2 \\
\hline Model 2 & 11.1 & -2.5 to 24.8 & 6.6 & -10.8 to 24.1 & $17.8^{\mathrm{C}}$ & 7.7 to27.9 & 3.6 & -12.3 to 19.7 & -5.7 & -13.8 to 2.4 & -17.6 & -38.7 to 3.5 \\
\hline \multicolumn{13}{|c|}{ HDL Cholesterol, mg/dL } \\
\hline Model 1 & $-5.2^{c}$ & -9.3 to -1.1 & -1.9 & -11.3 to 7.4 & $-5.9^{\mathrm{C}}$ & -11.1 to -0.7 & 0.8 & -6.4 to 8.1 & -0.1 & -3.4 to 3.2 & 3.9 & -5.3 to13.2 \\
\hline Model 2 & -4.9 & -9.3 to 0.5 & -2.1 & -12.2 to 7.9 & $\begin{array}{c}-6.0 \\
c\end{array}$ & -11.2 to -0.7 & 0.1 & -7.8 to 7.9 & 0.6 & -3.4 to 4.6 & 4.5 & -5.3 to 14.4 \\
\hline
\end{tabular}

\section{MetS Risk $z$ Score}

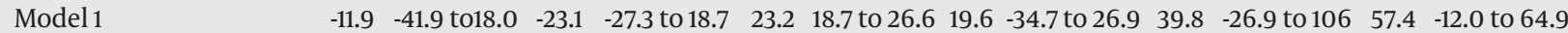

${ }^{\mathrm{a}}$ Abbreviations: Rf, reference group for comparison; NA, non-applicable; MP, mean percent; CI, confidence interval; BMI,body mass index; WC, waist circumference; SBP, systolic blood pressure; DBP, diastolic blood pressure; FBS, fasting blood glucose; TG, triglyceride; and MetS, metabolic syndrome.

b Model 1 was adjusted for age (continuous), smoking status (smoker, nonsmoker, and ex-smoker), physical activity (light, moderate, and heavy), education levels (primary and secondary, high school, and university), duration of change in marital status, and baseline variables. Model 2 was further adjusted for BMI.

c $\mathrm{P}<0.05$.

\section{Discussion}

Our findings showed that marital status might affect the MetS differently with regard to sex and occupations. In comparison to married males, consistently single males showed an incremental trend in BMI, WC, and TG concentrations without any changes in MetS risk $z$ score. In the transition to married status, there was also an incremental trend in BMI and WC in males and employed females; however, only employed females had an increase in MetS risk $z$ score.

Although several cross-sectional and longitudinal studies have shown that married subjects are more often overweight and obese than unmarried subjects (2428 ), others have reported that marriage is associated with many health benefits including decreased cardio- 
vascular morbidity and mortality (29). In their report, Ortega et al. observed that sex affects the relation between obesity, cardiometabolic risk (CMR) factors, and marital status (30). In the current study, consistently single males had increased BMI and WC in comparison with married males. Although levels of components of MetS including DBP and FBS had decreased, no significant changes were observed in MetS risk $z$ score in single males. Among consistently single females, both employed and unemployed, no significant changes in components of MetS and MetS risk $z$ score were observed in comparison to married females. In contrast, although the BMI increased in both sexes in the transition to married status, only employed females had an increase in MetS risk $z$ score over time. Our results were inconsistent with those of a prospective study that showed fitness levels had not changed among married females, but had declined in married males (30). In the Health and Lifestyle Survey, although single status was associated with a favorable profile including good health, high education level, and nonsmoker status, all-cause mortality was higher in comparison to married subjects (29). It is not still clear how marital status is associated with obesity and health status. However, healthy lifestyle such as healthy eating behavior might be sufficiently powerful to overshadow any detrimental effects of weight gains (31-33). In the ATTICA study, after controlling for eating patterns, no significant association was found between marital status and BMI as well as CVD risk factors, which implies that eating patterns may mediate the association between CVD risk factors and marital status (34). Physiologic pathways, based on the stress/social support model, may explain the effect of marital status on health (35).

Although previous studies had mostly focused on the association of marital status and marital transition with BMI and WC, the current study focused on the association of marital status and marital transition with other components of MetS including lipid profiles, FBS, SBP, DBP, and MetS risk $z$ score over time. Except a decrease in BP, we found no significant changes in components of MetS in employed or unemployed consistently single females over time; however, among females in the transition to married status, an increase in BMI and WC was observed. Consistent with a previous study (36), occupational status affected the association between marital transition and MetS among females in this study; employed females had significant increases in their MetS risk z score during follow-up, which was in line with previous studies that showed transition to marriage has a negative effect on health status $(30,37)$. Nonetheless, our findings were not consistent with those of some conducted studies in different countries. Reynolds et al. compared data from two similar epidemiologic surveys in elderly American and Japanese populations and showed that among Americans, marital status was associated with an increase in body weight, while there was not such an association among a Japanese population (38). Among British females, being single was significantly associated with higher all-cause mortality (29).

Marital transition may be associated with health changes. Marital termination, in terms of divorce or widowhood, has been associated with increase in CVD risk factors (34), unfavorable lipid profiles (39), higher BMI and WC (27), higher inflammation markers (39), and higher incidence of MetS (40) and CVD events (39). In the current study, we investigated the effect of consistently widowed/divorced status and transition out of marriage on CVD risk factors over time and found no differences in components of MetS and the MetS risk $z$ score among consistently divorced/widowed males and employed or unemployed females in comparison to married participants. However, in comparison with consistently married males,transition out of marriage was associated with increased BMI and WC in males. Therefore, components of MetS differed between participants with consistently widowed/divorced status and those with transition out of marriage status. This difference might explain the inconsistent results of the cross-sectional studies among divorced and widowed subjects because most studies had not considered the duration of changes in marital status $(28,41)$. In the current study, the transition out of married status was associated with increased BMI and WC; however, some components of Mets decreased among females. Contrary to our results, in a three-year follow-up study, transition out of marriage was associated with increase in fitness levels in males, whereas a tendency toward decreased fitness was observed among females (30). It was also shown that over a ten-year follow-up, males who had divorced had no statistically significant weight change in comparison to those who had remained consistently married (42). Another study reported that divorced males mirrored married ones in obesity status, while divorced females had lower odds of being overweight or obese than the married ones had (43). In contrast, while widowed males had almost equivalent risks for obesity and abdominal obesity than married males had (28), many more widowed females had the tendency to gain weight than married ones had $(28,44)$.

Our study had some limitations. First, nutrition data and in particular, energy intake was not gathered for all participants. Second, we could not investigate the relationship between components of MetS and childbearing among females, since data on parity were not available. In addition, data on outcomes of CVD was not available to draw a comparison among various marital statuses.

In conclusion, marital transition including "to or out of married status" is associated with an increased prevalence of CVD, especially among employed females. While consistent marital status is not associated with changes in CVD risks in females, further studies should investigate the association between marital status and 
outcomes of CVD and other non-communicable diseases.

\section{Acknowledgments}

The authors express appreciation to Miss N. Shiva for critical editing of English grammar and syntax of the manuscript.

\section{Authors' Contributions}

Study concept and design: Fereidoun Azizi and Somayeh Hosseinpour Niazi; analysis and interpretation of data: Somayeh Hosseinpour Niazi and Farhad Hosseinpanah;drafting of the manuscript: Somayeh Hosseinpour Niazi, Parvin Mirmiran, and Arefeh Fallah; critical revision of the manuscript for important intellectual content: Somayeh Hosseinpour Niazi, Parvin Mirmiran, Farhad Hosseinpanah, Arefeh Fallah, and Fereidoun Azizi;statistical analysis: Somayeh Hosseinpour Niazi and Farhad Hosseinpanah; and study supervision: Fereidoun Azizi.

\section{Funding/Support}

This study was supported in part by grant 750 from the Research Institute for Endocrine Sciences, Shahid Beheshti University of Medical Sciences, Tehran, Iran (Dr Azizi).

\section{References}

1. Grundy SM, Cleeman JI, Daniels SR, Donato KA, Eckel RH, Franklin BA, et al. Diagnosis and management of the metabolic syndrome: an American Heart Association/National Heart, Lung, and Blood Institute scientific statement: Executive Summary. Crit Pathw Cardiol. 2005;4(4):198-203.

2. Delavari A, Forouzanfar MH, Alikhani S, Sharifian A, Kelishadi R. First nationwide study of the prevalence of the metabolic syndrome and optimal cutoff points of waist circumference in the Middle East: the national survey of risk factors for noncommunicable diseases of Iran. Diabetes Care. 2009;32(6):1092-7.

3. Azizi F, Salehi P, Etemadi A, Zahedi-Asl S. Prevalence of metabolic syndrome in an urban population: Tehran Lipid and Glucose Study. Diabetes Res Clin Pract. 2003;61(1):29-37.

4. Heidari Z, Hosseinpanah F, Mehrabi Y, Safarkhani M, Azizi F. Predictive power of the components of metabolic syndrome in its development: a 6.5-year follow-up in the Tehran Lipid and Glucose Study (TLGS). Eur J Clin Nutr. 2010;64(10):1207-14.

5. Luk AO, So WY, Ma RC, Kong AP, Ozaki R, Ng VS, et al. Metabolic syndrome predicts new onset of chronic kidney disease in 5,829 patients with type 2 diabetes: a 5 -year prospective analysis of the Hong Kong Diabetes Registry. Diabetes Care. 2008;31(12):2357-61.

6. Zarich SW. Metabolic syndrome, diabetes and cardiovascular events: current controversies and recommendations. Minerva Cardioangiol. 2006;54(2):195-214.

7. Vimaleswaran KS, Radha V, Mohan V. Thr54 allele carriers of the Ala54Thr variant of FABP2 gene have associations with metabolic syndrome and hypertriglyceridemia in urban South Indians. Metabolism. 2006;55(9):1222-6.

8. Mohan V, Gokulakrishnan K, Deepa R, Shanthirani CS, Datta M Association of physical inactivity with components of metabolic syndrome and coronary artery disease--the Chennai Urban Population Study (CUPS no. 15). Diabet Med. 2005;22(9):1206-11.

9. Shepherd R. Influences on food choice and dietary behavior. Forum Nutr. 2005(57):36-43.
10. Booth SL, Sallis JF, Ritenbaugh C, Hill JO, Birch LL, Frank LD, et al Environmental and societal factors affect food choice and physical activity: rationale, influences, and leverage points. Nutr Rev. 2001;59(3 Pt 2):S21-39.

11. Lim H, Nguyen T, Choue R, Wang Y. Sociodemographic disparities in the composition of metabolic syndrome components among adults in South Korea. Diabetes Care. 2012;35(10):202835.

12. Gharipour M, Kelishadi R, Toghianifar N, Tavassoli AA, Khosravi AR, Sajadi F, et al. Socioeconomic disparities and smoking habits in metabolic syndrome: evidence from isfahan healthy heart program. Iran Red Crescent Med J. 2011;13(8):537-43.

13. Sygnowska E, Piwonska A, Waskiewicz A, Broda G. Socioeconomic factors and the risk of metabolic syndrome in the adult Polish population: the WOBASZ study. Kardiol Pol. 2012;70(7):718-27.

14. Buckland G, Salas-Salvado J, Roure E, Bullo M, Serra-Majem L. Sociodemographic risk factors associated with metabolic syndrome in a Mediterranean population. Public Health Nutr. 2008;11(12):1372-8.

15. Sirdah MM, Al Laham NA, Abu Ghali AS. Prevalence of metabolic syndrome and associated socioeconomic and demographic factors among Palestinian adults (20-65 years) at the Gaza Strip. Diabetes Metab Syndr. 2011;5(2):93-7.

16. Al-Daghri NM, Alkharfy KM, Al-Attas OS, Khan N, Alfawaz HA Alghanim SA, et al. Gender-dependent associations between socioeconomic status and metabolic syndrome: a cross-sectional study in the adult Saudi population. BMC Cardiovasc Disord. 2014;14:51.

17. Park MJ, Yun KE, Lee GE, Cho HJ, Park HS. A cross-sectional study of socioeconomic status and the metabolic syndrome in Korean adults. Ann Epidemiol. 2007;17(4):320-6.

18. Rguibi M, Belahsen R. Overweight and obesity among urban Sahraoui women of South Morocco. Ethn Dis. 2004;14(4):542-7.

19. Yang X, Tao Q, Sun F, Zhan S. The impact of socioeconomic status on the incidence of metabolic syndrome in a Taiwanese health screening population. Int J Public Health. 2012;57(3):551-9.

20. Azizi F, Rahmani M, Emami H, Mirmiran P, Hajipour R, Madjid $\mathrm{M}$, et al. Cardiovascular risk factors in an Iranian urban population: Tehran lipid and glucose study (phase 1). Soz Praventivmed. 2002;47(6):408-26.

21. Azizi F, Ghanbarian A, Momenan AA, Hadaegh F, Mirmiran P, Hedayati M, et al. Prevention of non-communicable disease in a population in nutrition transition: Tehran Lipid and Glucose Study phase II. Trials. 2009;10:5.

22. Ainsworth BE, Jacobs DR, Jr., Leon AS. Validity and reliability of self-reported physical activity status: the Lipid Research Clinics questionnaire. Med Sci Sports Exerc. 1993;25(1):92-8.

23. Franks PW, Ekelund U, Brage S, Wong MY, Wareham NJ. Does the association of habitual physical activity with the metabolic syndrome differ by level of cardiorespiratory fitness? Diabetes Care. 2004;27(5):1187-93.

24. Janghorbani M, Amini M, Rezvanian H, Gouya MM, Delavari A, Alikhani S, et al. Association of body mass index and abdominal obesity with marital status in adults. Arch Iran Med. 2008;11(3):274-81.

25. Martinez JA, Kearney JM, Kafatos A, Paquet S, Martinez-Gonzalez MA. Variables independently associated with self-reported obesity in the European Union. Public Health Nutr. 1999;2(1A):125-33.

26. Erem C, Arslan C, Hacihasanoglu A, Deger O, Topbas M, Ukinc K, et al. Prevalence of obesity and associated risk factors in a Turkish population (trabzon city, Turkey). Obes Res. 2004;12(7):111727.

27. Tur JA, Serra-Majem L, Romaguera D, Pons A. Profile of overweight and obese people in a Mediterranean region. Obes Res. 2005;13(3):527-36.

28. Tzotzas T, Vlahavas G, Papadopoulou SK, Kapantais E, Kaklamanou D, Hassapidou M. Marital status and educational level associated to obesity in Greek adults: data from the National Epidemiological Survey. BMC Public Health. 2010;10:732.

29. Cheung YB. Marital status and mortality in British women: a longitudinal study. Int J Epidemiol. 2000;29(1):93-9.

30. Ortega FB, Brown WJ, Lee DC, Baruth M, Sui X, Blair SN. In fitness and health? A prospective study of changes in marital status and 
fitness in men and women. Am J Epidemiol. 2011;173(3):337-44.

31. Friel S, Newell J, Kelleher C. Who eats four or more servings of fruit and vegetables per day? Multivariate classification tree analysis of data from the 1998 Survey of Lifestyle, Attitudes and Nutrition in the Republic of Ireland. Public Health Nutr. 2005;8(2):159-69.

32. Pollard J, Greenwood D, Kirk S, Cade J. Lifestyle factors affecting fruit and vegetable consumption in the UK Women's Cohort Study. Appetite. 2001;37(1):71-9.

33. Sofi F, Gori AM, Marcucci R, Innocenti G, Dini C, Genise S, et al. Adherence to a healthful life attenuates lipid parameters among a healthy Italian population. Nutr Metab Cardiovasc Dis. 2007;17(9):642-8.

34. Yannakoulia M, Panagiotakos D, Pitsavos C, Skoumas Y, Stafanadis $C$. Eating patterns may mediate the association between marital status, body mass index, and blood cholesterol levels in apparently healthy men and women from the ATTICA study. Soc Sci Med. 2008;66(11):2230-9.

35. Robles TF, Kiecolt-Glaser JK. The physiology of marriage: pathways to health. Physiol Behav. 2003;79(3):409-16.

36. Kalediene R, Petrauskiene J, Starkuviene S. Inequalities in mortality by marital status during socio-economic transition in Lithuania. Public Health. 2007;121(5):385-92.

37. Lee S, Cho E, Grodstein F, Kawachi I, Hu FB, Colditz GA. Effects of marital transitions on changes in dietary and other health behaviours in US women. Int J Epidemiol. 2005;34(1):69-78.

38. Reynolds SL, Hagedorn A, Yeom J, Saito Y, Yokoyama E, Crimmins EM. A tale of two countries--the United States and Japan: are differences in health due to differences in overweight? JEpidemiol. 2008;18(6):280-90.

39. Engstrom G, Hedblad B, Rosvall M, Janzon L, Lindgarde F. Occupation, marital status, and low-grade inflammation: mutual confounding or independent cardiovascular risk factors? Arterioscler Thromb Vasc Biol. 2006;26(3):643-8.

40. Troxel WM, Matthews KA, Gallo LC, Kuller LH. Marital quality and occurrence of the metabolic syndrome in women. Arch Intern Med. 2005;165(9):1022-7.

41. Mirmiran P, Mirbolooki M, Azizi F. Familial clustering of obesity and the role of nutrition: Tehran Lipid and Glucose Study. Int J Obes Relat Metab Disord. 2002;26(12):1617-22.

42. Sobal J, Rauschenbach B, Frongillo EA. Marital status changes and body weight changes: a US longitudinal analysis. Soc Sci Med. 2003;56(7):1543-55.

43. Averett SL, Sikora A, Argys LM. For better or worse: relationship status and body mass index. Econ Hum Biol. 2008;6(3):330-49.

44. Rissanen AM, Heliovaara M, Knekt P, Reunanen A, Aromaa A. Determinants of weight gain and overweight in adult Finns. Eur Clin Nutr. 1991;45(9):419-30. 